\title{
Influence of Three-Dimensional Coral Structures on Hyperspectral Benthic Reflectance and Water-Leaving Reflectance
}

\author{
John D. Hedley ${ }^{1, *}$, Maryam Mirhakak ${ }^{2}$, Adam Wentworth ${ }^{3}$ and Heidi M. Dierssen ${ }^{2}$ (D) \\ 1 Numerical Optics Ltd., Tiverton EX16 8AA, UK \\ 2 Department of Marine Sciences, University of Connecticut, Groton, CT 06340, USA; \\ ma.mirhakak@gmail.com (M.M.); heidi.dierssen@uconn.edu (H.M.D.) \\ 3 Materials Science and Engineering Department, University of Connecticut, Storrs, CT 06269, USA; \\ awentworth2@bwh.harvard.edu \\ * Correspondence: j.d.hedley@numopt.com; Tel.: +44-1884-675070
}

Received: 31 July 2018; Accepted: 30 September 2018; Published: 19 December 2018

Featured Application: Hyperspectral remote sensing of coral reefs. We present simplifying factors and guidance on handling or avoiding the potential variability in spectral reflectances caused by the structural nature of corals and illumination conditions. Results presented here can be implemented in remote sensing algorithms for bottom mapping of coral reefs, and guide data collection practice.

\begin{abstract}
Shading and inter-reflections created by the three-dimensional coral canopy structure play an important role on benthic reflectance and its propagation above the water. Here, a plane parallel model was coupled with a three-dimensional radiative transfer canopy model, incorporating measured coral shapes and hyperspectral benthic reflectances, to investigate this question under different illumination and water column conditions. Results indicated that a Lambertian treatment of the bottom reflectance can be a reasonable assumption if a variable shading factor is included. Without flexibility in the shading treatment, nadir view bottom reflectances can vary by as much as $\pm 20 \%$ (or $\pm 9 \%$ in above-water remote sensing reflectance) under solar zenith angles (SZAs) up to $50^{\circ}$. Spectrally-independent shading factors are developed for benthic coral reflectance measurements based on the rugosity of the coral. In remote sensing applications, where the rugosity is unknown, a shading factor could be incorporated as an endmember for retrieval in the inversion scheme. In dense coral canopies in clear shallow waters, the benthos cannot always be treated as Lambertian, and for large solar-view angles the bi-directional reflectance distribution functions (BRDF) hotspot propagated to above water reflectances can create up to a $50 \%$ or more difference in water-leaving reflectances, and discrepancies of $20 \%$ even for nadir-view geometries.
\end{abstract}

Keywords: remote sensing; hyperspectral; shallow water; coral; derivative; radiative transfer; canopy

\section{Introduction}

Remote sensing of coral reefs is an important complementary survey technique for science, monitoring, and management, being able to cover substantially larger areas than in-situ surveys albeit at lower accuracy [1,2]. A well-established paradigm in coral reef remote sensing is that hyperspectral data offers the best results for discrimination of both benthic habitats and specific benthic types, such as corals, algae, and sand [3,4]. Applied studies have shown that benthic habitat classification accuracy increases with the number of available spectral bands [3,5], specifically in the $400-700 \mathrm{~nm}$ range since the opacity of water beyond $700 \mathrm{~nm}$ limits use of NIR wavelengths to only the shallowest waters 
( $<2 \mathrm{~m})$. Habitats are broad mapping categories, whereas mapping of specific types, e.g., corals vs. algae, is very challenging since their spectral reflectances can be similar. Modelling and sensitivity analyses based on reflectance spectra measured, either in-situ using diver-operated spectroradiometers, or ex-situ in the lab, imply that spectral separation of benthic types by hyperspectral reflectances is possible $[4,6,7]$, and there are increasing numbers of applied demonstrations of discriminations of benthic types (e.g., coral, sand, and algae) from airborne hyperspectral imagery [8-14].

These studies imply that capability for discrimination of coral reef types is reliant on the discrimination of spectral features of the pigments that are present, such as peridinin in the coral symbionts, and accessory pigments of algae [8]. Pigment-based reflectance features are present at the surface of the corals and other benthic types, but the coral reef environment is structurally complex, with multiple benthic types typically present within even the highest spatial resolution imagery (e.g., pixels $1 \mathrm{~m}$ ). Vertical structure in the reef canopy and the benthic types themselves gives rise to shading, inter-reflections, and a generally complex interaction with the light environment $[15,16]$. Most sensitivity analyses to date work with empirically measured reflectances of individual types, at a scale roughly equivalent to their morphology, and use a linear mixing model, which essentially assumes that the individual types can be treated in the same way as a spatially flat Lambertian patchwork [4,7]. However, even in a carefully defined lab experiment, the linear mixing model does not always work well with structural components [17]. Given the complexity of light interaction with a mixed structural canopy, it is not immediately obvious to what extent a pigment based hyperspectral reflectance feature present at the scale of a coral surface translates to an above water measurement at remote sensing scales.

The purpose of the study presented here was to investigate propagation of hyperspectral reflectances from the surfaces of structural benthos (corals and surrounding substrate) to water leaving reflectance. The study combined a three-dimensional canopy model [18], with a plane parallel water-column model (HydroLight [19]) (Figure 1). The model was parameterized by 3D reconstructions of actual coral shapes and surface reflectances derived from hyperspectral images of the same corals. A variety of investigations were conducted (Table 1), to track the main factors that mitigate the transmission of hyperspectral features, and to justify practical simplifications to provide useful results that can be immediately applied in other contexts. Investigations included the effects of shading, and water attenuation and scattering, both in the region of individual corals and within mixtures of corals and surrounding substrates. The three-dimensional model was used to generate fully populated bi-directional reflectance distribution functions (BRDFs) of mixed canopies, and these were input to HydroLight to model above water reflectance for different depths, water inherent optical properties (IOPs), and solar-view geometries.

In summary, specific objectives were:

1. Investigate how the spectral reflectance at the scale of coral macro-morphology (shape) relates to coral surface-scale spectral reflectance.

2. Quantify the error arising from making simplifying modelling assumptions, such as using a single reflectance spectrum to represent a coral under different light environments, or excluding water attenuation and scattering between coral structures within the canopy.

3. Characterize the BRDF of assemblages of corals in different densities.

4. Apply those BRDFs as the bottom boundary in HydroLight, to model BRDF effects in the remote sensing reflectance arising from canopy BRDF properties in different depths and conditions.

The results indicated that whilst structural factors can introduce substantial variability in spectral reflectances, this variability can be avoided or accommodated by simplifying factors. The major variations in spectral reflectance over corals, due to structure and illumination, can be captured by incorporating a spectrally flat shading factor or black shade endmember into linear mixing models. Above-water BRDF effects on reflectance can be $20 \%$ or more for dense shallow canopies when viewing 
close to the solar plane in typical remote sensing solar-view geometries, but are less apparent if the solar-view geometry is at $90^{\circ}$ to the solar plane.

(I) Water-leaving reflectance $L_{\mathrm{w}}(\theta, \phi) / E_{\mathrm{d}}$

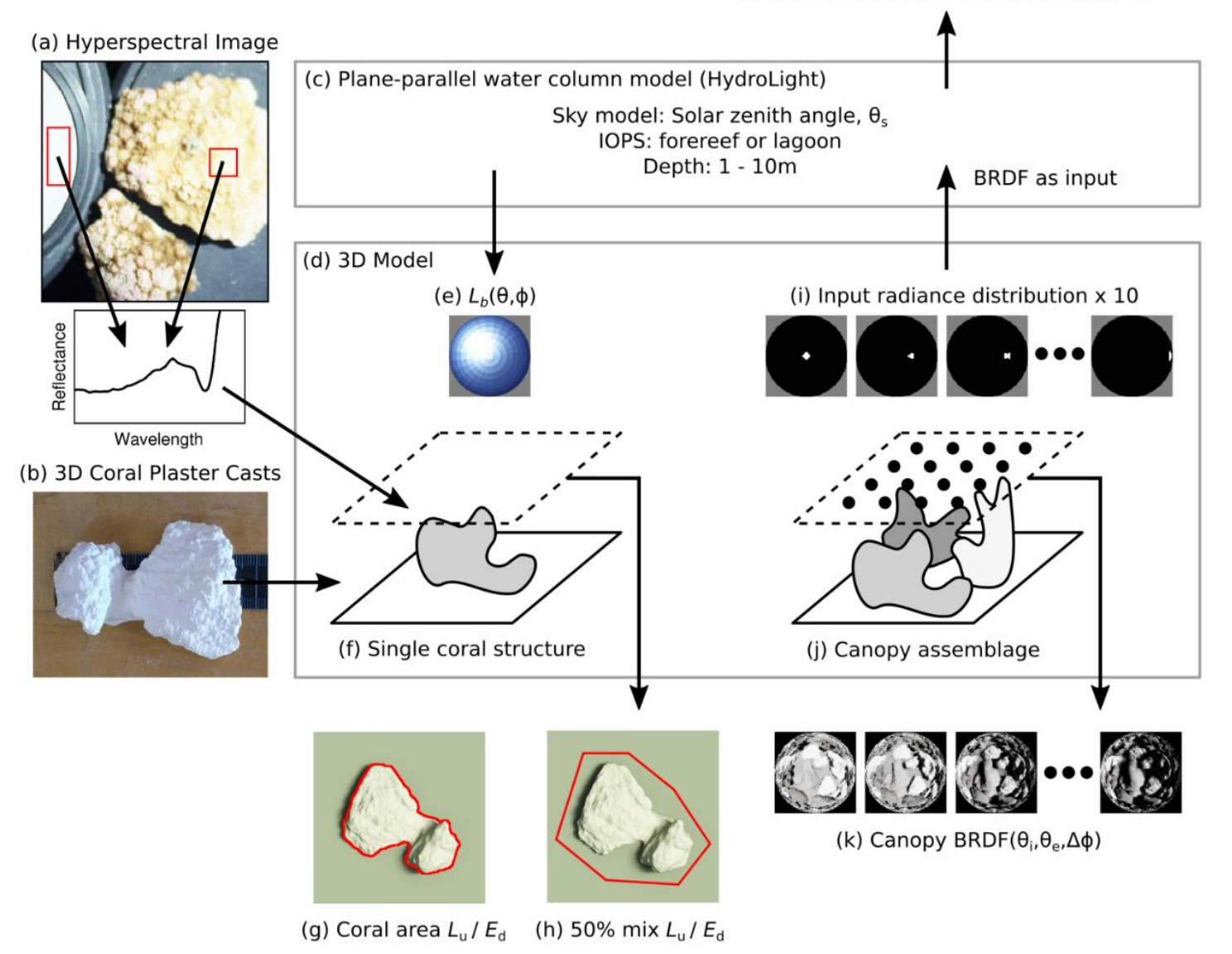

Figure 1. Model setup: (a) Coral surface reflectances were derived from hyperspectral image, and (b) shape from 3D reconstructions from plaster casts; (c) A plane parallel water column model was coupled with (d) a 3D canopy model in two ways: (1) (e) To model bottom of water column light fields over (f) single structures and estimate (g) reflectance over the coral and (h) of a 50\% mix with surrounding substrate; and (2) (i) Directional incident radiance at different angles over (j) assemblages of structures were used to characterize (k) the bi-directional reflectance distribution function (BRDF). The BRDF was then input to the water column model to give (l) water-leaving reflectances.

\section{Materials and Methods}

\subsection{Overview}

Toward the aims listed above, three-dimensional models of actual coral shapes were input to a 3D canopy radiative transfer model [18] coupled to a plane-parallel water column model, HydroLight [19]. Six different modelling exercises were conducted (Table 1, Figure 1). These were structured to progressively incorporate complexity and justify the design of subsequent modelling steps: from reflectance over a single coral shape only, to then including substrate, then include assemblages of corals, and finally the water column. Intermediate results from these activities also provided results of interest, for example, on the validity of using a linear mixing model for bottom of water column reflectance. The following sections give details on the input data and model set up. 
Table 1. Different properties and treatments modelled in this study and the aim of each investigation. "Res." indicates if the high- or low-resolution coral structure models were used. "I." indicates if interstitial scattering and attenuation by the water around the coral shapes was included (N-No, Y-Yes). "Position" indicates the notional location of the estimated reflectance.

\begin{tabular}{|c|c|c|c|c|c|}
\hline & Modelled Property & Res. & I. & $\begin{array}{l}\text { Derived Reflectance and } \\
\text { Purpose of Activity }\end{array}$ & Position \\
\hline 1 & \multirow{2}{*}{$\begin{array}{l}\text { Reflectance averaged over each of the } 16 \text { coral shapes, for the } \\
\text { coral area only (substrate masked out). Bottom of water } \\
\text { column incident radiance distribution generated by } \\
\text { HydroLight with } 32 \text { treatments, combining: Solar zenith } \\
\text { angles } 10^{\circ} \text { and } 50^{\circ} \text {; depths } 1 \mathrm{~m} \text { and } 10 \mathrm{~m} \text {; forereef and lagoon } \\
\text { IOPs; and four rotational positions of the coral shape. }\end{array}$} & high & $\mathrm{N}$ & $\begin{array}{l}\pi L_{\mathrm{u}} / E_{\mathrm{d}} \\
\text { Effect of shape on reflectance } \\
\text { over coral area only. }\end{array}$ & $\begin{array}{l}\text { above } \\
\text { canopy }\end{array}$ \\
\hline 2 & & low & $\mathrm{N}$ & $\begin{array}{l}\pi L_{\mathrm{u}} / E_{\mathrm{d}} \\
\text { Effect of resolution of } \\
\text { 3D models. }\end{array}$ & $\begin{array}{l}\text { above } \\
\text { canopy }\end{array}$ \\
\hline 3 & \multirow{2}{*}{$\begin{array}{l}\text { Reflectance averaged over a single coral shape, plus in each } \\
\text { case, surrounding substrate to give a } 50 \% \text { mix in terms of } \\
\text { areal cover. Incident radiance distributions as above. }\end{array}$} & low & $\mathrm{N}$ & $\begin{array}{l}\pi L_{\mathrm{u}} / E_{\mathrm{d}} \\
\text { Validity of linear mixing model } \\
\text { for reflectance over coral and } \\
\text { surrounding substrate. }\end{array}$ & $\begin{array}{l}\text { above } \\
\text { canopy }\end{array}$ \\
\hline 4 & & low & Y & $\begin{array}{l}\pi L_{\mathrm{u}} / E_{\mathrm{d}} \\
\text { Effect of ignoring water } \\
\text { scattering and attenuation } \\
\text { within canopy. }\end{array}$ & $\begin{array}{l}\text { above } \\
\text { canopy }\end{array}$ \\
\hline 5 & $\begin{array}{l}\text { Azimuthally averaged BRDF function for six canopy } \\
\text { assemblages ranging from } 39 \% \text { to } 75 \% \text { coral cover. BRDF } \\
\text { tabulated in HydroLight standard directional discretization. }\end{array}$ & low & $\mathrm{N}$ & $\begin{array}{l}\pi \operatorname{BRDF}\left(\theta_{\mathrm{i}}, \theta_{\mathrm{e}}, \Delta \varphi\right) \\
\text { Demonstrate canopy BRDF } \\
\text { effects and generate function for } \\
\text { input to HydroLight. }\end{array}$ & $\begin{array}{l}\text { above } \\
\text { canopy }\end{array}$ \\
\hline 6 & $\begin{array}{l}\text { Above-water remote sensing reflectance as a function of } \\
\text { solar-view geometry, depth, and IOPs, for six canopy BRDFs } \\
\text { generated as above. }\end{array}$ & low & $\mathrm{N}$ & $\begin{array}{l}\pi L_{\mathrm{W}}\left(\theta_{\mathrm{s}}, \theta_{\mathrm{v}}, \Delta \varphi\right) / E_{\mathrm{d}} \\
\text { Demonstrate above water BRDF } \\
\text { effects under typical solar-view } \\
\text { geometries. }\end{array}$ & $\begin{array}{l}\text { above } \\
\text { water }\end{array}$ \\
\hline
\end{tabular}

\subsection{Coral Surface Reflectances and Shape}

The three-dimensional shape and surface reflectance of 16 corals were used as input to the model. Live corals of various species, including Porites compressa, Porites evermanni, and Montipora capitate, were sampled from Mahukona Beach Park, Potters, and Pauko Bay Boat Ramp in Big Island, Hawaii, in February 2017. For the purposes of this paper, corals were grouped based on sampling depth, referred to as shallow ' $\mathrm{S}$ ' ( $<8 \mathrm{~m}$ ) or deep ' $\mathrm{D}$ ' (10 to $20 \mathrm{~m}$ ) (Table 2). For practical reasons the corals were relatively small $(<20 \mathrm{~cm}$ diameter). Corals were stored in open buckets filled with natural salt water and kept in a cool water bath that was shaded from the direct sun. Coral samples were imaged in the air, immediately after being removed from the water, using a tripod-mounted 710 hyperspectral imager (Surface Optics Corporation). This instrument records an image cube of $520 \times 696$ pixels with spectral information at 128 spectral bands, and with $5 \mathrm{~nm}$ spacing from 380 to $1040 \mathrm{~nm}$. All images were made under natural illumination at noon $\pm 2 \mathrm{~h}$, to minimize any shading effects on the coral surfaces. Images were obtained within $24 \mathrm{~h}$ of collection, and before any noticeable degradation. A Labsphere Spectralon ${ }^{\mathrm{TM}}$ Diffuse Reflectance Standard with a reflectance value of $20 \%$ was placed in the image frame during each measurement (Figure 1a). Using the reference, for each coral, a single surface reflectance, $R(\lambda)$, i.e., the reflectance at the scale of the coral surface, assuming the surface is locally flat, was estimated by taking the mean over one or more small areas of the image where the coral surface was relatively horizontal (Figure 1a). While in reality, the reflectance over a coral surface is typically variable, in the scope of this study, we were interested in the effect of coral macro-morphology and canopy structure on reflectance. Hence, each coral was treated as if it had a uniform surface reflectance. The availability of horizontal areas for extracting surface reflectance possibly biased the measured reflectances slightly, but the sample areas where sufficiently large to mitigate small scale influences, such as low pigmented apical polyps (Figure 1a). For the underlying substrate, a spectral reflectance of dead coral rock was used, this data was from a previous study, collected with a GER 1500 spectroradiometer as described in Reference [17]. All spectra were resampled to 168 bands in $2 \mathrm{~nm}$ intervals from $400 \mathrm{~nm}$ to $736 \mathrm{~nm}$, as this was the spectral resolution of the modelling software. 
Table 2. Coral shapes used in this study. "Group" indicates grouping based on depth of collection, shallow $(S,<8 \mathrm{~m})$ or deep (D, 10-20 m). Coral 03 was from a site subjected to terrestrial run-off and was not placed in either group. Polygon counts for the high- and low-resolution models are given. The final column is discussed in the results and is the maximum percentage difference that choice of resolution leads to in reflectance averaged over the coral area in any band.

\begin{tabular}{|c|c|c|c|c|c|c|}
\hline \multirow{2}{*}{ ID } & \multirow{2}{*}{ Species } & \multicolumn{3}{|c|}{ Polygon Count } & \multirow[t]{2}{*}{ Rugosity } & \multirow{2}{*}{$\begin{array}{c}\text { Max } L_{\mathbf{u}} / E_{\mathrm{d}} \text { Difference } \\
\text { Low vs. High }\end{array}$} \\
\hline & & Group & Low Res. & High Res. & & \\
\hline 03 & Montipora capitata & $\mathrm{n} / \mathrm{a}$ & 2306 & 152,185 & 1.98 & 0.36 \\
\hline 08 & Porites evermanni & $\mathrm{D}$ & 1712 & 69,945 & 2.74 & 0.51 \\
\hline 10 & Porites evermanni & $\mathrm{D}$ & 1832 & 75,524 & 2.16 & 0.28 \\
\hline 11 & Montipora capitata & $\mathrm{D}$ & 1830 & 103,394 & 1.77 & 0.29 \\
\hline 12 & Porites evermanni & $\mathrm{D}$ & 2150 & 51,954 & 2.16 & 0.24 \\
\hline 16 & Porites compressa & $\mathrm{D}$ & 1454 & 89,703 & 5.43 & 1.33 \\
\hline 17 & Porites evermanni & $\mathrm{S}$ & 2079 & 124,092 & 2.05 & 0.27 \\
\hline 18 & Porites compressa & $\mathrm{D}$ & 1898 & 103,430 & 5.82 & 0.47 \\
\hline 19 & Porites evermanni & $\mathrm{S}$ & 1804 & 183,283 & 1.61 & 0.22 \\
\hline 31 & Porites compressa & $\mathrm{D}$ & 1226 & 56,726 & 2.96 & 0.43 \\
\hline 32 & Montipora capitata & $\mathrm{S}$ & 2461 & 100,886 & 2.01 & 0.31 \\
\hline 33 & Porites compressa & $S$ & 2160 & 98,502 & 2.90 & 0.47 \\
\hline 35 & Pocillopora sp. & S & 2966 & 240,353 & 3.06 & 0.21 \\
\hline 38 & Porites evermanni or lutea & $S$ & 1908 & 95,265 & 1.72 & 0.17 \\
\hline 39 & Montipora patula & $S$ & 2264 & 133,594 & 1.81 & 0.39 \\
\hline 40 & Porites evermanni or lutea & $S$ & 1403 & 56,696 & 1.45 & 0.17 \\
\hline
\end{tabular}

To capture the shape of each field-sampled coral, they were impressed into silicone rubber putty after imaging and the moulds were allowed to air dry. These moulds were transported back to the University of Connecticut; each mold was filled with plaster to recreate the coral shape (Figure 1b). Digital 3D models of the plaster cast of natural corals were created using Autodesk ReCapTM photogrammetry software (version 5.0.1.30). The process involved taking between 20 and 40 overlapping photographs of the plaster corals and converting them into 3D digital models consisting of a mesh of vertices and triangular surface polygons. Then, the 3D models were edited in Autodesk ${ }^{\circledR}$ MeshmixerTM (version 3.4.35) to isolate the coral shape from the background. For each coral, two models were produced: High resolution, ranging from 50,000 to 200,000 triangles, and low-resolution, typically $\sim 2000$ triangles (Table 1). The low-resolution models are computationally easier to handle, and the first intended test was to determine if low-resolution models would be sufficient. For interpretation of results, a surface rugosity measure [20] was calculated for each coral shape, being the ratio of the coral surface area to its projected area (i.e., nadir view areal extent) in the high-resolution models.

\subsection{Radiative Transfer Modelling}

The radiative transfer modelling was split into two components: (1) a three-dimensional canopy model designed to evaluate optical properties just above the canopy or above individual coral structures (Figure 1d) [18,21], and (2) a plane-parallel water column model (Figure 1c), HydroLight [19]. All modelling was conducted hyperspectrally in 168 bands of $2 \mathrm{~nm}$ step, from 400 to $736 \mathrm{~nm}$.

The 3D model has been described and used in a number of previous publications [18,21-23]. The solution method involves breaking down all surfaces and volumes into discrete elements, triangular surface polygons (as already provided by the 3D digital models), and cubic voxels, for scattering and attenuating media (the water). In this application, the coral shapes were placed on a flat underlying substrate that was decomposed into $100 \times 100$ squares (each being two triangles) over an area of approximately $20 \mathrm{~cm} \times 20 \mathrm{~cm}$. The model domain can either have light incident from above with horizontally periodic boundaries (i.e., the model set-up repeats in all horizontal directions), or be embedded into a "far-field" radiance distribution characterized from all directions (appropriate for modelling an isolated structure). The model is solved by calculating light transfer between all pairs of elements and propagating the incident light through the system by iteration, 
for a predetermined number of passes or until convergence is detected. Surfaces are treated as locally Lambertian, but volumetric elements embody full directional scattering, according to a scattering coefficient combined with a phase function [18]. As an update to previous work, this model is now implemented on modern Graphics Processing Units (GPUs), which facilitates improved performance on computationally demanding applications with many bands and elements.

Since the coral structures were small ( $20 \mathrm{~cm}$ max. height), it would be inefficient to use the 3D model for the full water column, since depths up to $10 \mathrm{~m}$ were of interest. More efficiently, the 3D model was coupled to HydroLight in two ways:

1. HydroLight was used to generate a bottom of water column radiance distribution, and this was used to illuminate the individual coral structures, standing on flat dead coral substrate, by being used as the input radiance boundary condition (Figure 1e,f). From these model runs, the reflectance over the coral structure was determined under different illumination conditions to deduce the average reflectance and its variability due to shading and other effects, across a range of illumination conditions (Figure 1g,h). Treatments were applied corresponding to the range limits of interest: Depths of $1 \mathrm{~m}$ and $10 \mathrm{~m}$; solar zenith angles of $10^{\circ}$ and $50^{\circ}$, azimuth angles of $0^{\circ}, 90^{\circ}, 180^{\circ}, 270^{\circ}$, and two sets of Inherent Optical Properties (IOPs) denoted "forereef" and "lagoon" (described below). Water surface roughness was set to correspond to a wind speed of $5 \mathrm{~ms}^{-1}$ but note that only water leaving radiance was used in the results, so surface reflectance was excluded. This method was used for tests 1 to 4 , listed in Table 1.

2. Mixtures of 3D living coral structures were assembled on flat dead coral rock substrate, in areal cover densities from $39 \%$ to $75 \%$. The 3D model was used with horizontal periodic boundaries to generate a canopy BRDF function, which was then used as a bottom boundary condition in HydroLight (Figure 1i,j). By this method, spectral water-leaving reflectances derived as water-leaving radiance at a given wavelength $(\lambda)$ normalized to downwelling planar irradiance $\left(L_{\mathrm{w}}(\theta, \Delta \varphi, \lambda) / E_{\mathrm{d}}(\lambda)\right)$, could be derived above the water for different view directions under different solar zenith angles and water column conditions (Figure 11). Incorporating the water column this way spatially averages the results, and scope of the results corresponds to pixels larger than the coral structures, i.e., pixels $\geq 1 \mathrm{~m}$, since the coral structures were less than $20 \mathrm{~cm}$ across. This modelling covered the same range of depths, solar zenith angles, and the two IOP treatments mentioned above. This aspect of the work corresponds to activities 5 and 6 in Table 1.

One important test was to determine if water attenuation and scattering within the canopy, i.e., at the scale of, and in between, coral shapes was at all important with respect to the derived reflectances. The 3D model can incorporate volumetric absorption and scattering but it is computationally slow, especially for computations in 168 bands. The "interstitial" IOPs were incorporated by embedding the shape in a mesh of $16 \times 16 \times 16$ voxels in activity 4 (Table 1), with IOPs consistent with the corresponding HydroLight modelling (see below). In the other modelling activities, interstitial IOPs were not included. Since the coral shapes were small, within the canopy path lengths of only a few centimeters through the water were achieved. Scattering is predominantly in the forward direction so on short path lengths it has very little effect; the primary issue was absorption on the paths between surface patches. An absorption coefficient of 0.4 (approximately as at $700 \mathrm{~nm}$ ) gives losses of just $4 \%$ on a $10 \mathrm{~cm}$ path, so whilst it was not expected that excluding interstitial IOPs would have a substantial effect, a specific test was conducted, and this is evaluated in the results section.

\subsection{Inherent Optical Properties}

The two IOP treatments "forereef" and "lagoon" (Figure 2) were configured using the HydroLight 5.3 New Case 2 model [19] to produce total absorption, $a(\lambda)$, and attenuation, $c(\lambda)$, values very similar to representative AC-S measurements taken in forereef and lagoon locations at Glovers Reef in Belize and in Palau, Micronesia in 2006 [7]. Both treatments had chlorophyll set at $0.12 \mathrm{mg} \cdot \mathrm{m}^{-3}$, but the lagoon treatment had more scattering and more coloured dissolved organic matter (CDOM). The independent 
$\mathrm{CDOM} a_{\mathrm{g}}(440)$ (not associated with phytoplankton) was $0.008 \mathrm{~m}^{-1}$ for forereef and $0.04 \mathrm{~m}^{-1}$ for lagoon, scattering was introduced by a calcareous sand component of 0.01 and $0.4 \mathrm{mg} \cdot \mathrm{m}^{-3}$, respectively. These component concentrations were derived by trial and error to produce bulk IOPs close to the measured values, which represented the limit of the range for high clarity (forereef) and high scattering (lagoon) in the AC-S dataset (see figures in [7]). Under the scattering phase function, Petzold's phase function was used throughout, as described in Reference [24]. These IOPs were within the range of those measured across different reefs of the Pacific [25].

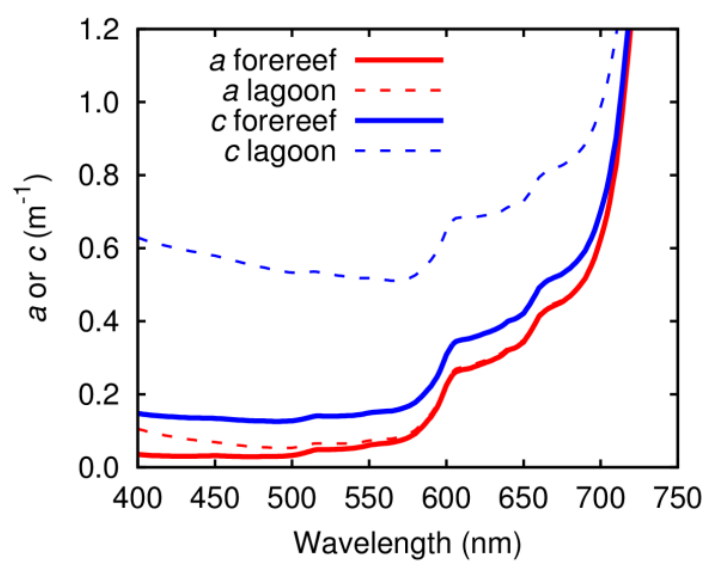

Figure 2. Total absorption, $a(\lambda)$, and attenuation, $c(\lambda)$, as used in the two water column inherent optical property (IOP) treatments, forereef and lagoon (includes the contribution of pure water itself).

\subsection{Coral Canopy Assemblages}

Incorporating individual corals into a water column model would correspond to a single coral surrounded by an infinite extent of bare substrate, which is not a situation of practical interest for remote sensing. Propagation of reflectance through a plane-parallel water column model, such as HydroLight, necessitates constructing a "pseudo plane-parallel" canopy to characterize a horizontally invariant bottom boundary BRDF. To this aim, six assemblages of corals on flat substrate were constructed by randomly manually placing and rotating the individual low-resolution coral models in an area of $20 \mathrm{~cm} \times 20 \mathrm{~cm}$ (periodically repeating). Three assemblages were generated using corals from the shallow group, and three from the deep group. Viewed from above, the areal cover of the corals versus the substrate varied from $39 \%$ to $75 \%$. Assemblages were named based on the group and percentage cover, specifically: S46, S58, S75, D39, D46, D74. There was no intention to specifically compare or construct any hypothesis concerning the shallow and deep groups, but it was considered prudent to be consistent and not to mix deep corals with shallow. The assemblages contained between 7 and 15 individual coral shapes, where some shapes appeared twice or three times in specific assemblages, but in different rotational positions. These randomly constructed canopies may not be strictly representative of a real canopy, but they do incorporate a mixture of typical coral morphologies and surface reflectances and enable an estimate of the optical properties of assemblages of such structures. In these models the total number of surface polygons, including substrate, varied from 35,000 to 68,000 .

\subsection{Coral Model Outputs and Processing}

For activities 1 to 4 (Table 1), the main output of interest was reflectance just above the canopy under naturalistic illumination conditions, for a typical range of situations, i.e., the kind of reflectance that could be used as a simple bottom reflectance boundary condition in a remote sensing model (Figure $1 \mathrm{~g}, \mathrm{~h}$ ). The key questions were if this reflectance was consistent under different illumination conditions (hence robust), and the extent of the effect of shading and other spectral mixing processes due to structure. Toward this aim, for each coral shape and illumination treatment, the model 
generated a $512 \times 512$ pixel hyperspectral nadir-view image of the coral in orthographic projection (no perspective) (Figure 1g,h). For activities 1 to 3, the upward radiance directly above the coral shape only (no substrate) was extracted from this image and averaged to give an average nadir view upward radiance, $L_{\mathrm{u}}(\lambda)$, over the coral shape. Reflectance was calculated as $L_{\mathrm{u}}(\lambda) / E_{\mathrm{d}}(\lambda)$ and multiplied by $\pi$, for the purpose of comparing to the surface scale diffuse reflectance. For activity 4 , which was concerned with spectral mixing with the substrate reflectance (Table 1), the upward radiance was averaged over the shape plus enough surrounding substrate to make a $50 \%$ areal cover mix between the coral shape and substrate (Figure $1 \mathrm{~h}$ ). The extent of this area was manually determined as a roughly consistent border around the shape. Activities 1 to 4 illuminated corals with azimuth angles of $0^{\circ}, 90^{\circ}$, $180^{\circ}$, and $270^{\circ}$, so shadows and other effects would be variable between these repeats, corresponding to the same shape illuminated from different directions.

The evaluation of BRDFs required that the full BRDF function be tabulated in a form suitable to use as input to HydroLight. HydroLight requires azimuthally averaged BRDFs, i.e., as a function of relative azimuth only, so the form of the function is BRDF $\left(\theta_{\mathrm{i}}, \theta_{\mathrm{e}}, \Delta \varphi\right)$ (units sr ${ }^{-1}$ ) in terms of quad-averaged radiance in the HydroLight directional discretization (directional segments of $\left.10^{\circ} \times 15^{\circ},[19]\right)$. The incident and exitant zenith angles are denoted by $\theta_{\mathrm{i}}$ and $\theta_{\mathrm{e}}$, and only the relative azimuth angle, $\Delta \varphi$, is relevant. The $3 \mathrm{D}$ model can work directly with the input and output quad-averaged radiances, where a single run of the model illuminates the canopy with radiance from a single directional quad, and the full hemisphere of exitant quad-averaged radiances is averaged over a $5 \times 5$ grid of points over the canopy (Figure 1k), see Reference [21] for more details. A minimum of 10 model runs can populate the azimuthally averaged function, one run for each incident zenith angle quad position, $\theta_{\mathrm{i}}$ (Figure 1i). Here, three runs per zenith angle were conducted with the canopy rotated by $120^{\circ}$ each time. Mirror image symmetry was assumed $\operatorname{BRDF}\left(\theta_{\mathrm{i}}, \theta_{\mathrm{e}}, \Delta \varphi\right)=\operatorname{BRDF}\left(\theta_{\mathrm{i}}, \theta_{\mathrm{e}}\right.$, $-\Delta \varphi)$, and the reciprocity condition $\operatorname{BRDF}\left(\theta_{\mathrm{i}}, \theta_{\mathrm{e}}, \Delta \varphi\right)=\operatorname{BRDF}\left(\theta_{\mathrm{e}}, \theta_{\mathrm{i}},-\Delta \varphi\right)$ was checked to ensure there were no major errors and then enforced. Each value in the final function was the average of 12 values in general, although not all values were independent.

\section{Results and Discussion}

\subsection{Effect of Coral Shape on Nadir View Reflectance}

Pseudo-color renderings of the $512 \times 512$ pixel images used to derive the upward radiance over the corals are shown in Figure 3. These model outputs are for high resolution 3D models, for one of the 32 bottom of water column illumination treatments. The RGB images were derived from the 168 band model output by forming the product of the spectrum in each pixel with red, green, and blue visual tristimulus functions [24]. The surface reflectance for some corals was darker than the substrate reflectance, e.g., coral 03 (Figure 3), but for most, the coral surface reflectance was lighter. The necessity of obtaining the reflectance from a horizontal surface area in the hyperspectral image (Figure 1a) may bias the reflectance compared to the true total surface average, but this is of minor consequence in this study, since the overall brightness of the reflectance is of secondary importance to the spectral shape. 

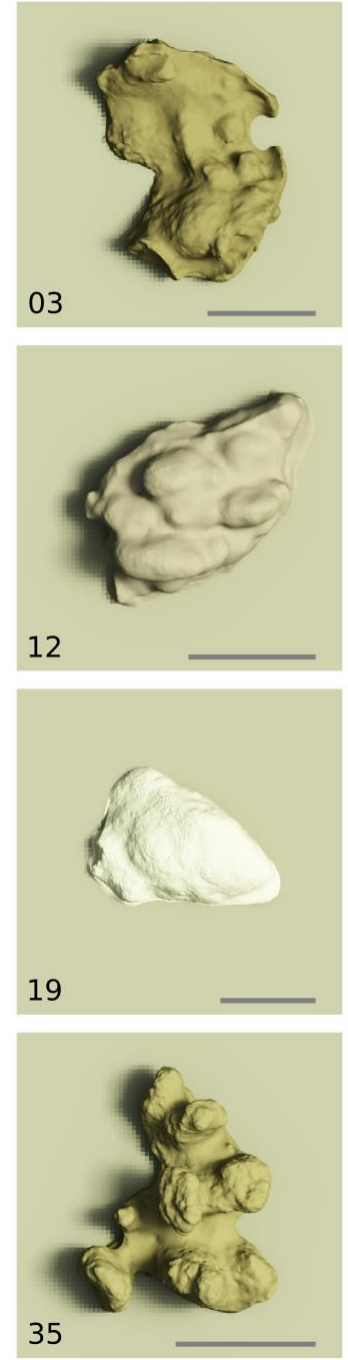
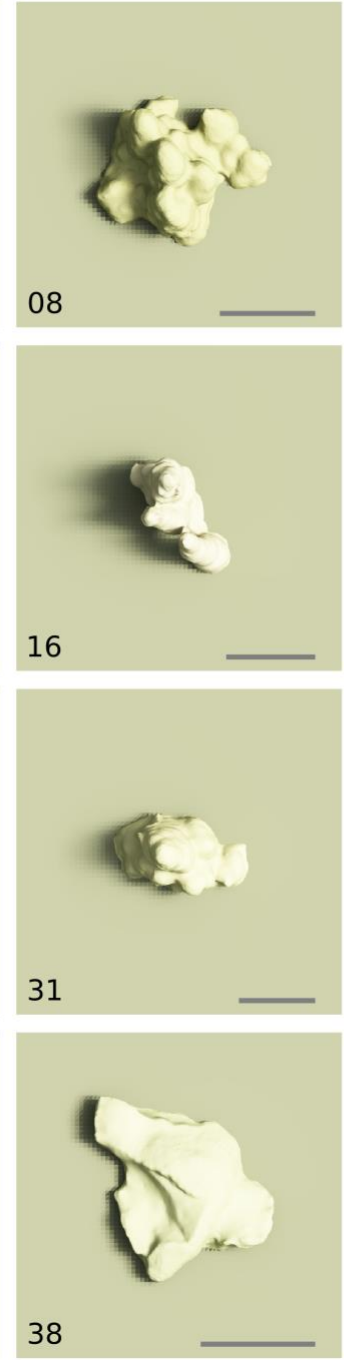
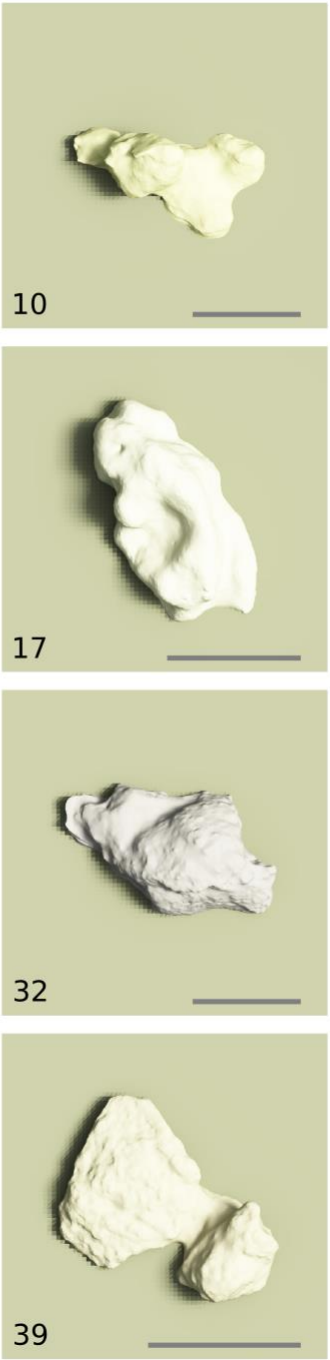
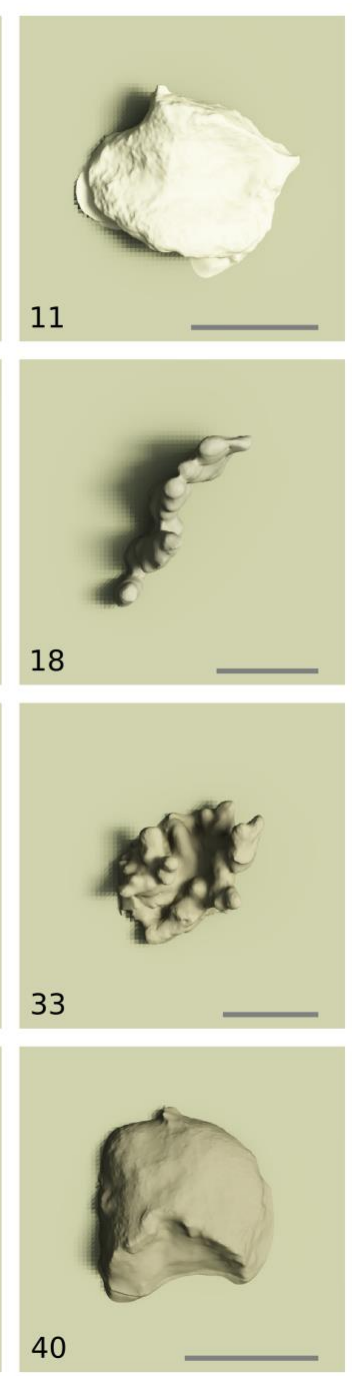

Figure 3. High resolution model outputs, as a nadir-view orthogonal projected rendering above each coral, converted to RGB using the tristimulus functions [24]. Illumination conditions are solar zenith $\theta_{\mathrm{s}}=50^{\circ}$, forereef IOPs, depth $1 \mathrm{~m}$. These are the high-resolution models without interstitial IOPs (activity 1, Table 1). Note: Corals are not shown in the same relative scale, bar is $5 \mathrm{~cm}$.

With respect to the modelled reflectance over the coral area (Figure 1g), for all corals, the spectra averaged over the coral area had a very similar shape to the coral surface reflectance but was darker due to shading within the coral structure (Figure 4). The different illumination conditions introduced some variability in the reflectance but in general, this variability was small and certainly smaller than the shading effect. Coral 16 had the highest variability in reflectance under different illuminations, as this coral was a relatively vertical structure with an overall irregular shape when viewed from above; therefore the level of shading was quite dependent on azimuth angle of the incident light. Regarding corals shapes that were flatter (e.g., coral 39), or with numerous protrusions (coral 35), different lighting conditions produced little variation in the average reflectance (Figure 4).The first useful observation from these results was that in general, the average reflectance over the coral shape up to $690 \mathrm{~nm}$ can be represented by a scaled version of the surface reflectance, where the scaling factor $<1$ effectively introduces shading as a black endmember in a linear mixing model, i.e., the transformation of surface reflectance $R(\lambda)$ is of the form $R^{\prime}(\lambda)=R(\lambda) \times f$, where $0 \leq f \leq 1$ and for a flat Lambertian surface $f=1$. Shading endmembers have been used in mineral applications [26]. For each coral, a single scaling factor was deduced as the median value of the fit from 400 to $690 \mathrm{~nm}$ to each of the 32 treatments (Table 3, Figure 4). These scaling factors varied from 0.50 (coral 16) to 0.84 (coral 39), 
and for flatter coral shapes, the scaling factor was higher since less shading was introduced. Corals 18 and 31, which were also relatively vertical structures, had scaling factors of 0.59 and 0.54 , respectively. Above $690 \mathrm{~nm}$, the fit to the simple shadow model was not as good, as reflectances over the coral area tended to be higher (Figure 4). It is likely the reason for this is the very high coral surface reflectance above $690 \mathrm{~nm}$ (Figure 4). A part of the coral surface that is shaded will "see" in its hemispherical field of view other parts of the coral surface. In wavelengths where the coral surface is highly reflective, those surrounding surfaces will reflect light to the point in question, and so the shading effect will be less overall.
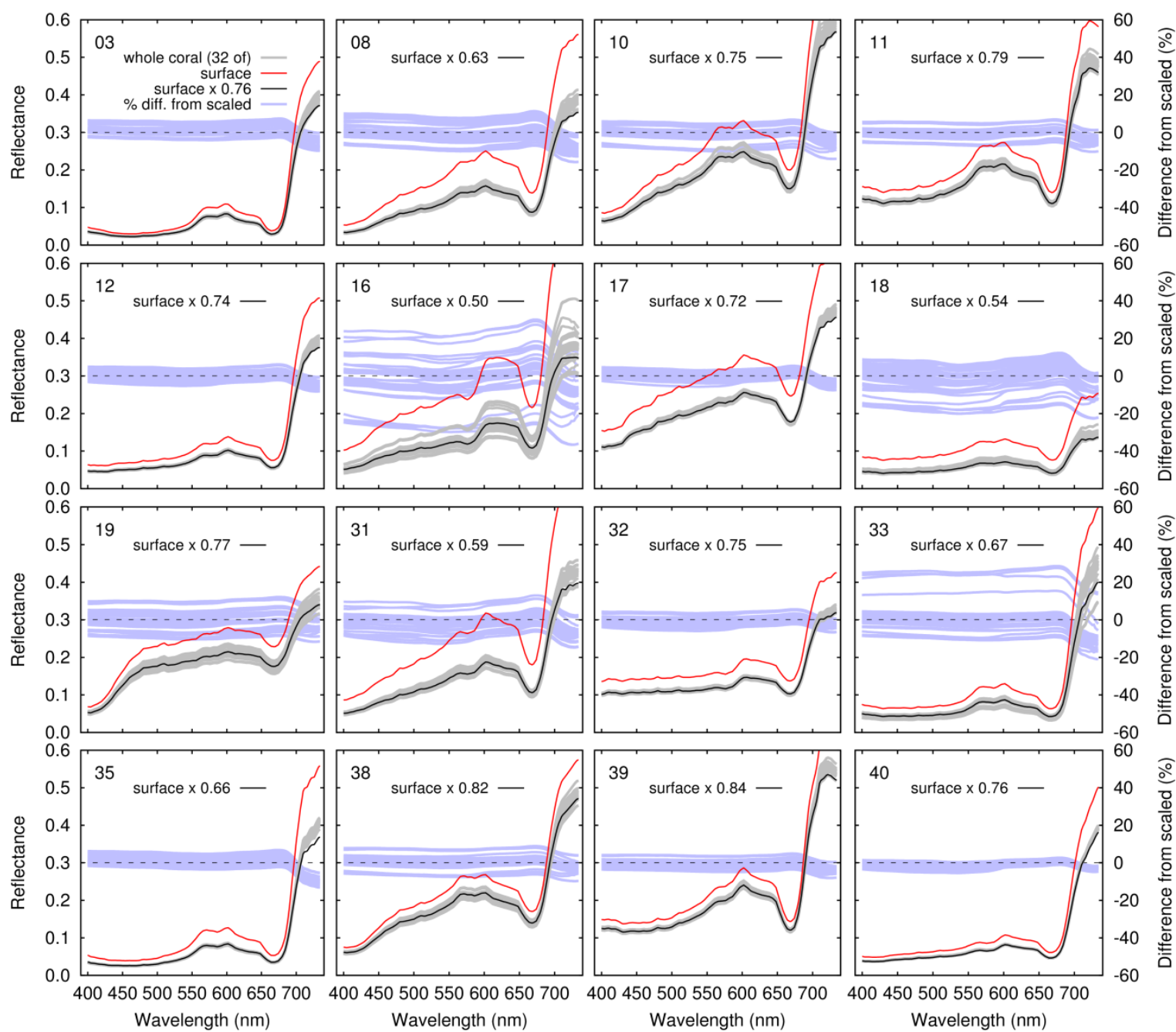

Figure 4. Reflectance over coral shape area only (no substrate) at the bottom of the water column with no interstitial water scattering or attenuation included. Plots show surface reflectance (red), reflectance over coral area under 32 treatments (grey), surface reflectance scaled by shading factor (black), and \% difference of each treatment from scaled surface reflectance (light blue, right hand y-axis).

In each coral, most of the reflectances under different illumination conditions were within $\pm 20 \%$ of the surface reflectance scaled by the mean shade factor (Figure 4). This shading factor, which in our data ranges from 0.50 to 0.84 , could be of immediate use in approaches that use diffuse reflectance as a bottom boundary condition, for example, model inversion techniques for image processing [27]. If basic inputs are surface reflectances, a variable shading factor (effectively a shade endmember) could be included as an additional parameter to be estimated in the inversion, or fixed at a reasonable value, e.g., $~ 0.7$, or certainly less than one. A variable factor would not only accommodate the difference between the coral shapes shown here but would also accommodate the residual error in each coral, 
due to variation under illumination conditions (Figure 4). However, this also points to the importance of the design of in-situ methodologies used for collection of spectral reflectance data $[10,11,28,29]$. Protocols which include multiple sampling over benthos will likely include a certain amount of the shading factor already, but this is scale-dependent, i.e., for small branching corals it may be completely included, whereas for larger massive morphologies the measurements may be closer to surface reflectances. Moreover, protocols that use shading or artificial light sources may or may not include the relevant amount of shading for a remote sensing context. Careful consideration of the relative scale of measurements in the context of the application is required. From our results, the maximum error in the brightness of the endmember reflectance, when using a surface scale reflectance instead of macro-morphology scale, could be a factor of as much as 0.5 (or 2). It may be worthwhile to consider if spectral libraries should be standardized or normalized in this respect, to either include or not include the shading factor. With this information, there would be the possibility to apply a post-hoc factor, at least as a rough estimate (between 0.5 and 0.84 in our data, e.g., $\sim 0.67$ ), or as a species-specific value (Table 3). Another consideration is that for very high spatial resolution imagery (pixels $\leq 0.5 \mathrm{~m}$ ), where benthic structure is at a similar scale to the pixels, shading effects may vary from pixel to pixel, over for example large massive corals, where the sides and top may be imaged in different pixels.

Table 3. Shading factors for coral area only and coral with surrounding substrate in $50 \%$ mix. Final column shows the maximum difference in the reflectance of any band up to $690 \mathrm{~nm}$, when interstitial attenuation and scattering is included in the canopy model.

\begin{tabular}{|c|c|c|c|c|c|c|}
\hline \multirow[t]{2}{*}{ ID } & \multirow[t]{2}{*}{ Species } & \multicolumn{2}{|c|}{$\begin{array}{l}\text { Shading Scale Factor } \\
\text { Coral only }\end{array}$} & \multicolumn{2}{|c|}{$\begin{array}{l}\text { Shading Scale Factor } \mathbf{5 0 \%} \\
\text { Coral-Substrate Mix }\end{array}$} & \multirow[t]{2}{*}{$\begin{array}{c}\text { Max } L_{\mathrm{u}} / E_{\mathrm{d}} \text { diff. with } \\
\text { Interstitial IOPs }(\leq 690 \mathrm{~nm})\end{array}$} \\
\hline & & Range & Median & Range & Median & \\
\hline 03 & Montipora capitata & $0.71-0.79$ & 0.76 & $0.83-0.88$ & 0.85 & $2.6 \%$ \\
\hline 08 & Porites evermanni & $0.57-0.69$ & 0.63 & $0.68-0.77$ & 0.74 & $2.8 \%$ \\
\hline 10 & Porites evermanni & $0.71-0.82$ & 0.75 & $0.75-0.84$ & 0.81 & $1.6 \%$ \\
\hline 11 & Montipora capitata & $0.75-0.84$ & 0.79 & $0.80-0.85$ & 0.84 & $1.0 \%$ \\
\hline 12 & Porites evermanni & $0.71-0.77$ & 0.74 & $0.79-0.85$ & 0.82 & $1.7 \%$ \\
\hline 16 & Porites compressa & $0.39-0.66$ & 0.50 & $0.51-0.64$ & 0.59 & $3.1 \%$ \\
\hline 17 & Porites evermanni & $0.69-0.75$ & 0.72 & $0.75-0.79$ & 0.78 & $1.0 \%$ \\
\hline 18 & Porites compressa & $0.50-0.65$ & 0.54 & $0.55-0.68$ & 0.65 & $3.0 \%$ \\
\hline 19 & Porites evermanni & $0.69-0.85$ & 0.77 & $0.78-0.86$ & 0.83 & $1.9 \%$ \\
\hline 31 & Porites compressa & $0.54-0.65$ & 0.59 & $0.64-0.71$ & 0.70 & $2.8 \%$ \\
\hline 32 & Montipora capitata & $0.72-0.78$ & 0.75 & $0.79-0.83$ & 0.81 & $1.2 \%$ \\
\hline 33 & Porites compressa & $0.51-0.74$ & 0.67 & $0.71-0.81$ & 0.78 & $2.6 \%$ \\
\hline 35 & Pocillopora sp. & $0.62-0.68$ & 0.66 & $0.70-0.81$ & 0.74 & $2.1 \%$ \\
\hline 38 & Porites evermanni or lutea & $0.76-0.88$ & 0.82 & $0.82-0.87$ & 0.86 & $1.5 \%$ \\
\hline 39 & Montipora patula & $0.81-0.88$ & 0.84 & $0.83-0.88$ & 0.87 & $0.7 \%$ \\
\hline 40 & Porites evermanni or lutea & $0.75-0.79$ & 0.76 & $0.87-0.89$ & 0.88 & $1.7 \%$ \\
\hline
\end{tabular}

\subsection{Effect of 3D Model Resolution}

To determine if the low-resolution 3D coral models were sufficient, the modelling of reflectance over coral shape area (Figure 1g, results in Figures 3 and 4, and Table 3) was duplicated using the low-resolution versions of the coral 3D structures (activity 2, Table 1). Across all corals and illumination treatments, the difference in any band when using the low-resolution 3D models was not greater than $0.51 \%$, apart from coral 16 which had a maximum difference of $1.33 \%$. In most corals, the maximum difference was less than a third of a per cent (Table 2, final column). Visually the outputs were very similar (Figure 5). Therefore, in general, using the low-resolution structures made almost no difference to the reflectance averaged over the coral area, and there seemed little need to continue using the high-resolution models, which with up to $\sim 100,000$ polygons cause the 3D radiative transfer model to run substantially slower. For this reason, the remaining modelling activities used only the low-resolution models. 


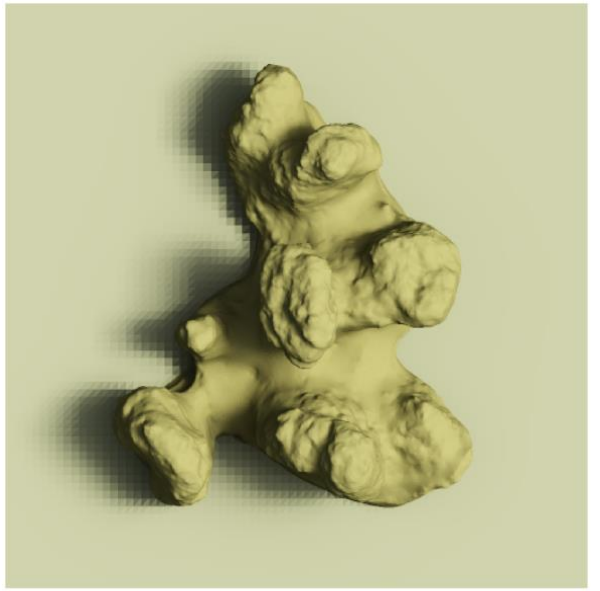

(a) high resolution (240353 triangles)

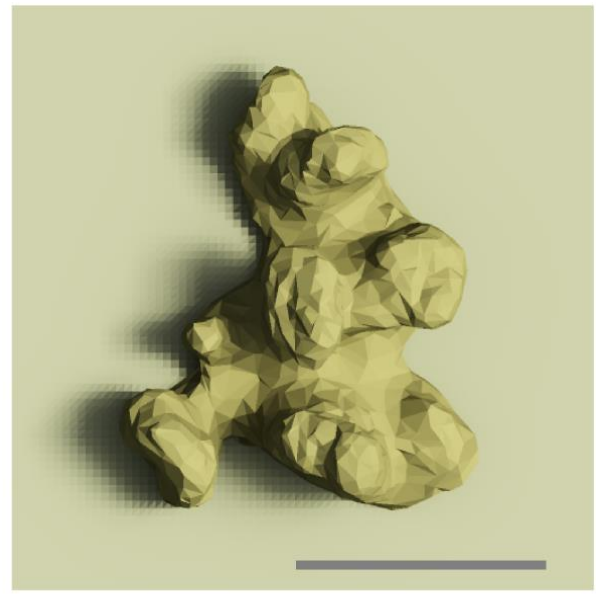

(b) low resolution (2966 triangles)

Figure 5. (a) High-resolution model versus; (b) low-resolution model of coral 35, scale bar is $5 \mathrm{~cm}$.

\subsection{Linear Mixing of Reflectance over Coral Shapes and Surrounding Substrate}

As with the reflectance over the coral shape only, reflectance over a $50 \%$ areal mix of coral and surrounding substrate was consistently darker than a 50\% linear mix of the surface reflectances, but could be well represented in wavelengths less than $690 \mathrm{~nm}$ by a uniformly scaled version of that linear mix (Figure 6). The shading factor when substrate was included was a consistently higher value (less shading) than the values over coral shape only, where the median for each coral ranged from 0.59 (coral 16) to 0.88 (coral 40 ) (Table 3). Individual values were from $4 \%$ to $20 \%$ higher than the corresponding values over the coral area only. This occurred because the flat substrate does not introduce any shading itself but is shaded by the coral structure (Figure 3). Including surrounding substrate introduces relatively less shading than would occur within the area of the structure. Therefore, both in the experimental set-up and the physical world, the shading factor is likely dependent on the ratio of coral cover to substrate.

The previous suggestion of including a variable black shade endmember in a linear mixing model for bottom reflectance would seem to be further supported by these findings. The shading factor is dependent on the areal cover of flat substrate included, and the difference was variable from $4 \%$ to $20 \%$. A-priori inclusion of the shading factor, even by careful collection of in-situ spectra to include shadows, cannot account for the variability due to structural context. However, again the figures presented here assume that the basic input reflectances are surface reflectances, where for flat substrates such as sand or dead coral rock this is likely to be the case, whilst for corals some a-priori inclusion of shading is likely. The possible range of shading factors would have to be modified accordingly.

Figure 7 shows that median shading factors were a clear function of surface rugosity (coral surface area divided by projected top-down area) for the reflectance over the coral area only (Figure 7a), and for coral shape and substrate mixes (Figure $7 \mathrm{~b}$ ). Intuitively, the shading factor should be 1 when rugosity is 1 (flat surface), and very high rugosities should tend to show some positive shading factor greater than zero. To express these constraints, a simple two-factor negative exponential model was fit to the plots in Figure 7, of which $y=(1-A) \times(\exp [-S \times(x-1)]+A$, fit for $S$ (slope) and, $A$, the asymptotic shading factor. This function gives a good fit in both cases but is just indicative of the general shape of the relationship, since the validity of the concept of an asymptotic shading factor is debatable. The slightly reduced shading effect when flat substrate is included, can be seen in the smaller magnitude slope $(S)$ of the best-fit line in Figure $7 \mathrm{~b}$. Note the surface rugosity value refers only to the coral shape. If rugosity in Figure $7 \mathrm{~b}$ were calculated incorporating the flat substrate, the rugosity values would be lower and the relationship would be closer to Figure $7 \mathrm{a}$. Solar zenith angle of $10^{\circ} \mathrm{vs}$. $50^{\circ}$ only had a small effect on the shading factor (Figure $7 \mathrm{~b}$ ), but as expected the effect increased with higher rugosity. Several factors were relevant to the observed small effect of the solar zenith angle, i.e., 
due to refraction the corresponding sub-surface zenith angles are less, at approximately $7^{\circ}-35^{\circ}$, and side-ward illumination reduces the irradiance on some surface facets, but at the same time increases it on others. Considering Figure 2, produced with $\theta_{\mathrm{S}}=50^{\circ}$, for most corals, only a small part of the area is actually visibly in shadow. Those with the most shaded area correspond to those where solar zenith angle has the most effect, e.g., corals 08,33 , and 35 , corresponding to the group with rugosity $\sim 3$ in Figure $7 \mathrm{~b}$. Overall Figure 7 indicates that rugosity, or equivalently species morphology, can be a robust indicator of the magnitude of the appropriate shading factor. This is consistent with empirical studies on BRDFs, which have shown that morphology and shadowing between branches are key determiners of spectral reflectance [16]. If a variable shading factor could be reliably estimated as a black endmember contribution in a model inversion image analysis [27], this estimate would carry information on benthic rugosity and benthic type.
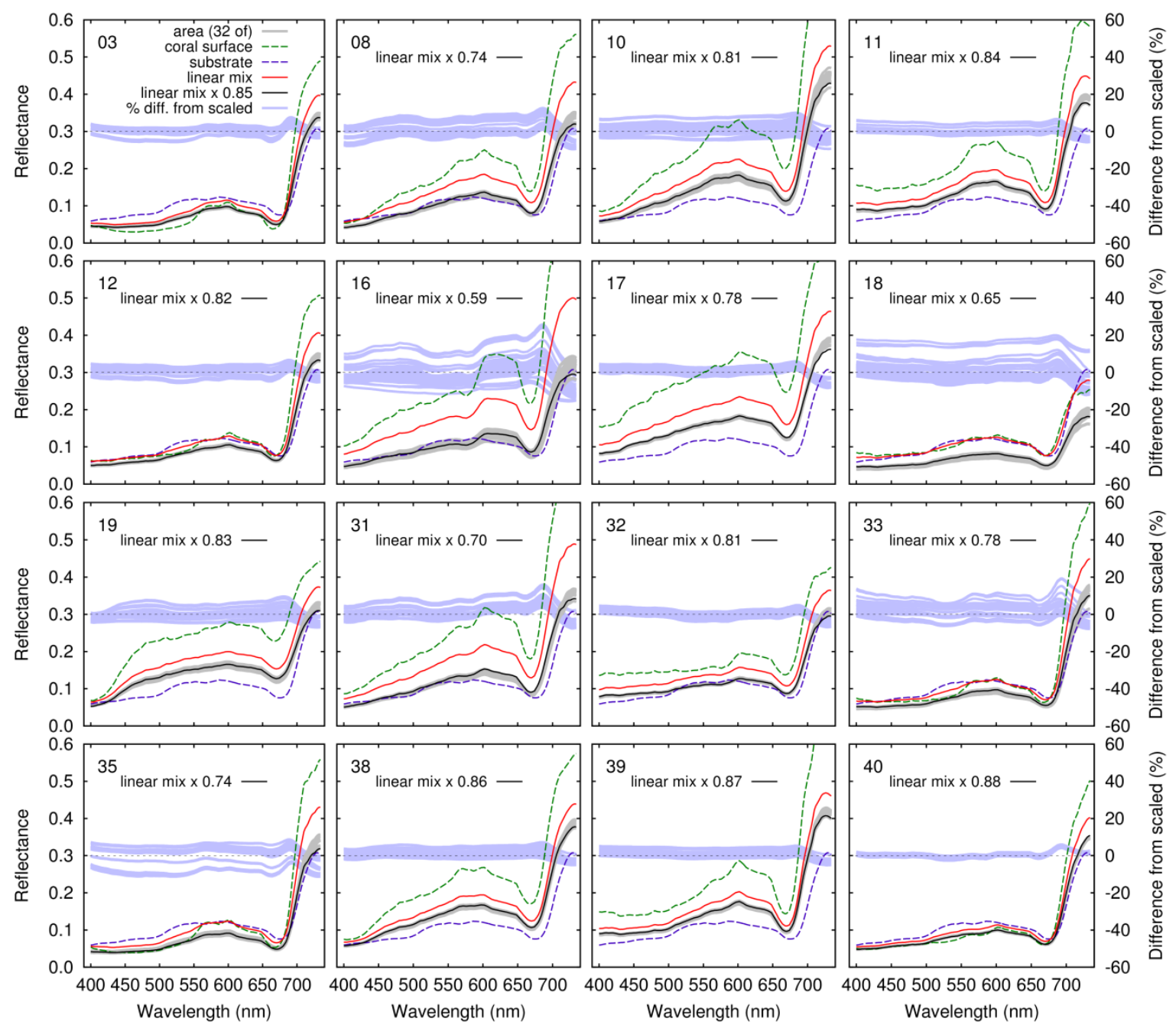

Figure 6. Reflectance over coral structure and surrounding substrate to give a $50 \% \mathrm{mix}$ in areal cover. Plots show the coral surface and substrate surface reflectances (thin and thick green lines), and a 50\% linear mix of those reflectances (red), reflectance over the coral and substrate area under 32 treatments (grey), surface reflectance scaled by shading factor (black), and \% difference of each treatment from scaled surface reflectance (light blue, right hand y-axis). 

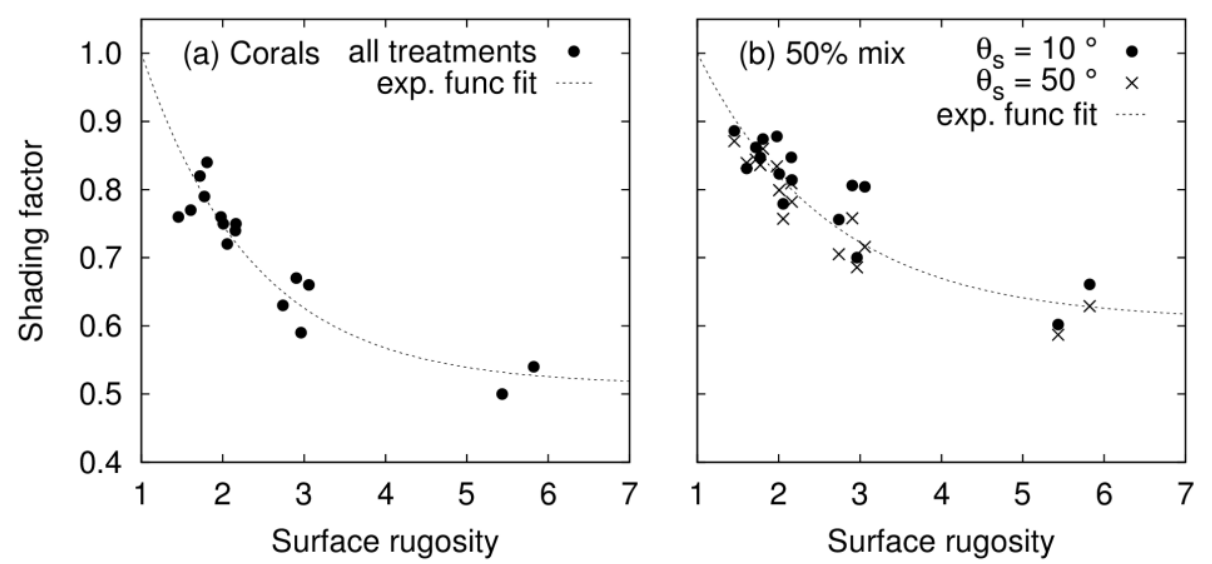

Figure 7. Median shading factor as a function of surface rugosity: (a) Over coral area only (Figure 4), and; (b) over coral area and surrounding substrate in a 50\% areal mix (Figure 6) with data separated into solar zenith angles of $10^{\circ}$ and $50^{\circ}$. Lines are of the form $y=(1-A) \times \exp [-S \times(x-1)]+A$ and are the least squares best fit, giving (a) $A=0.51, S=0.72$; (b) $A=0.61, S=0.61$.

\subsection{Effect of Interstitial Scattering and Absorption}

The difference when including interstitial IOPs (scattering and absorption in the water around and within the coral shape) in the modelling of reflectance averaged over a $50 \%$ mix of coral and substrate was in general, less than 3\% in any band for wavelengths less than $690 \mathrm{~nm}$ (Table 3), and for most coral shapes of the order of $2 \%$ or less. This showed that the previous back-of-envelope calculation that suggested a $4 \%$ error at $700 \mathrm{~nm}$, based on absorption over path lengths of $10 \mathrm{~cm}$, was quite reasonable. Beyond $700 \mathrm{~nm}$, absorption by pure water is high and the discrepancy when omitting interstitial IOPs became larger, up to $5 \%$. However, in a practical application, unless corals almost touch the water surface, the absorption in the water column above the canopy will dominate over the within-canopy effect, so the discrepancies above $690 \mathrm{~nm}$ are of minor consequence. The cost of $2 \%$ or $3 \%$ in accuracy when omitting the interstitial IOPs comes at the advantage, not only of substantially faster computation in the 3D model, but also the BRDF of the canopy can be decoupled from the IOPs of the overlying water column. That is, a BRDF can be computed based on coral canopy structure and surface reflectance, and then the overlying water column can be specified with independently varying IOPs. Therefore, this answers point 4 in Table 1 , and is the strategy that was taken in the BRDF and water column modelling activities ( 5 and 6 in Table 1). However, this result is scale dependent and only holds in this case because the coral structures were small. With larger corals and reef structures, where the vertical distances can be a meter or more, the effect of interstitial water scattering absorption is likely a more significant component of the reflectance.

\subsection{Canopy Assemblage BRDF Effects}

The discussion so far has concentrated on nadir view bottom of water column reflectance over individual corals under naturalistic light conditions, calculated based on the upward directed radiance and downward irradiance, i.e., $\pi L_{\mathrm{u}}(\lambda) / E_{\mathrm{d}}(\lambda)$. Whilst the previous results were fairly insensitive to illumination conditions, such as solar zenith angle (Figures 4 and 6), view angle effects were not considered. Direct use of these results as a bottom boundary requires the assumption of Lambertian reflectance. As such, they are appropriate for incorporation into models where this assumption is implicit, for example, in model inversion techniques for image analysis [27]. However, to correctly model propagation of light through the water column in a physically exact model, such as HydroLight, the full BRDF of canopy assemblages is required (activities 5 and 6, Table 1).

The BRDF function is calculated using light incident only for a specific direction in an otherwise black radiance field (Figure 1i), so in the model outputs, shading effects are very apparent (Figure 8). Visually, Figure 8 may appear to contradict Figure $7 \mathrm{~b}$, since shading as a function of incident zenith 
angle in Figure 8 appears stronger than implied by Figure $7 \mathrm{~b}$. To reconcile this first note that Figure $7 \mathrm{~b}$ is expressed in terms of above-surface solar zenith angles of $10^{\circ}$ and $50^{\circ}$, and so most closely corresponds to Figure $8 \mathrm{a}, \mathrm{b}$ (sub-surface incident angles of $10^{\circ}$ and $30^{\circ}$ ), Figure $8 \mathrm{c}$ is a more extreme example. Furthermore, Figure 8 arises from unidirectional illumination, whereas Figure $7 \mathrm{~b}$ arises from a more diffuse illumination, being the sub-surface propagated solar and sky illumination. A final point is that the increased shadow from Figure $8 \mathrm{a}$ to $8 \mathrm{~b}$, although visually very apparent, is probably not more than $10 \%$ of the actual image area, so even under unidirectional illumination it likely would not affect the shading factor by more than $10 \%$, which is comparable to the differences seen for rugosities $\sim 3$ in Figure $7 \mathrm{~b}$.

(a) $\theta_{\mathrm{i}}=10^{\circ}$

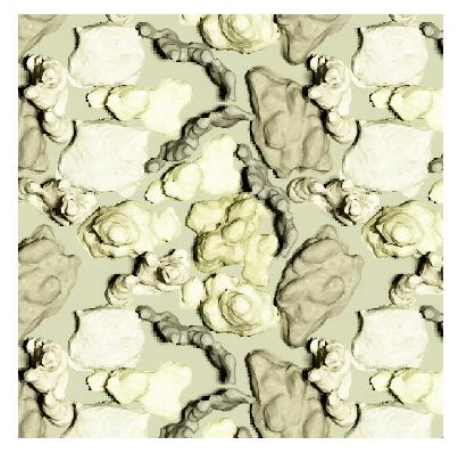

(b) $\theta_{i}=30^{\circ}$

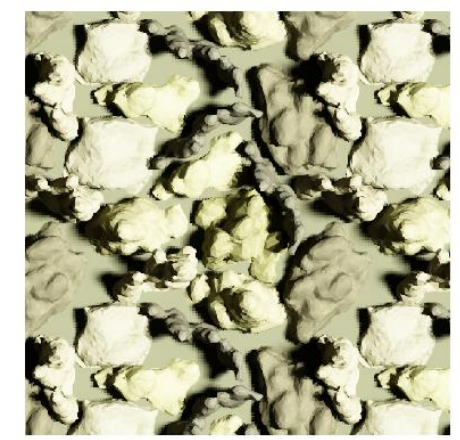

(c) $\theta_{\mathrm{i}}=50^{\circ}$

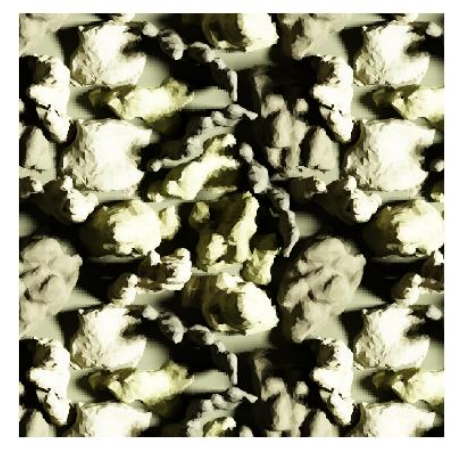

Figure 8. Examples from BRDF generation of canopy using reflectances of deep corals at $74 \%$ coral coverage (D74). Shown as nadir-view $\left(\theta_{\mathrm{e}}=0^{\circ}\right)$ orthogonal projected rendering above each canopy, corresponding to incident radiance from: $(\mathbf{a}) \theta_{i}=10^{\circ} ;(\mathbf{b}) \theta_{i}=30^{\circ}$ and; (c) $\theta_{i}=50^{\circ}$, respectively, azimuth $\varphi s=0^{\circ}$. RGB images are created from hyperspectral data using the tristimulus functions and represent an area of $30 \mathrm{~cm} \times 30 \mathrm{~cm}$.

One of the densest canopy assemblages, D74 (74\% coral cover), also tended to have vertically higher coral structures and consequentially showed the strongest BRDF effect, with an almost linear effect of view angle in the incident plane $(\Delta \varphi=0)$, when incident light was at a $50^{\circ}$ zenith angle (Figure 9e). The reflected radiance decreased by a factor of seven when varying the view direction from almost horizontal in the same direction as the incident light, to horizontally toward the incident light (Figure 9e). In all canopy assemblages there is a clear hotspot effect [30], where brightness is at a maximum when the incident and view directions are the same. The BRDFs discussed here were spatially averaged, and the hot spot occurs because the viewing geometry determines the fraction of shadowed area detected. When the viewing and incident light directions are the same, shadows are maximally obscured by the illuminated surfaces. Interestingly, for the canopy structures modelled here, the hotspot effect is stretched out to larger view angles (Figure 9). This is likely a geometrical consequence of an increasingly horizontal view onto vertical structures illuminated from the side (Figure 8).

In all canopy assemblages, there were only small BRDF effects at $90^{\circ}$ to the incident plane $\left(\Delta \varphi=90^{\circ}\right)$ (Figure $\left.9 \mathrm{~b}, \mathrm{~d}, \mathrm{f}\right)$. Typically reflectance decreased slightly as the view angle moved from nadir, although the pattern was stronger for denser canopies, such as D74 (Figure 9), and even included a slight increase in reflectance close to horizontal, being a pattern also seen in models of dense seagrass canopies [21]. 

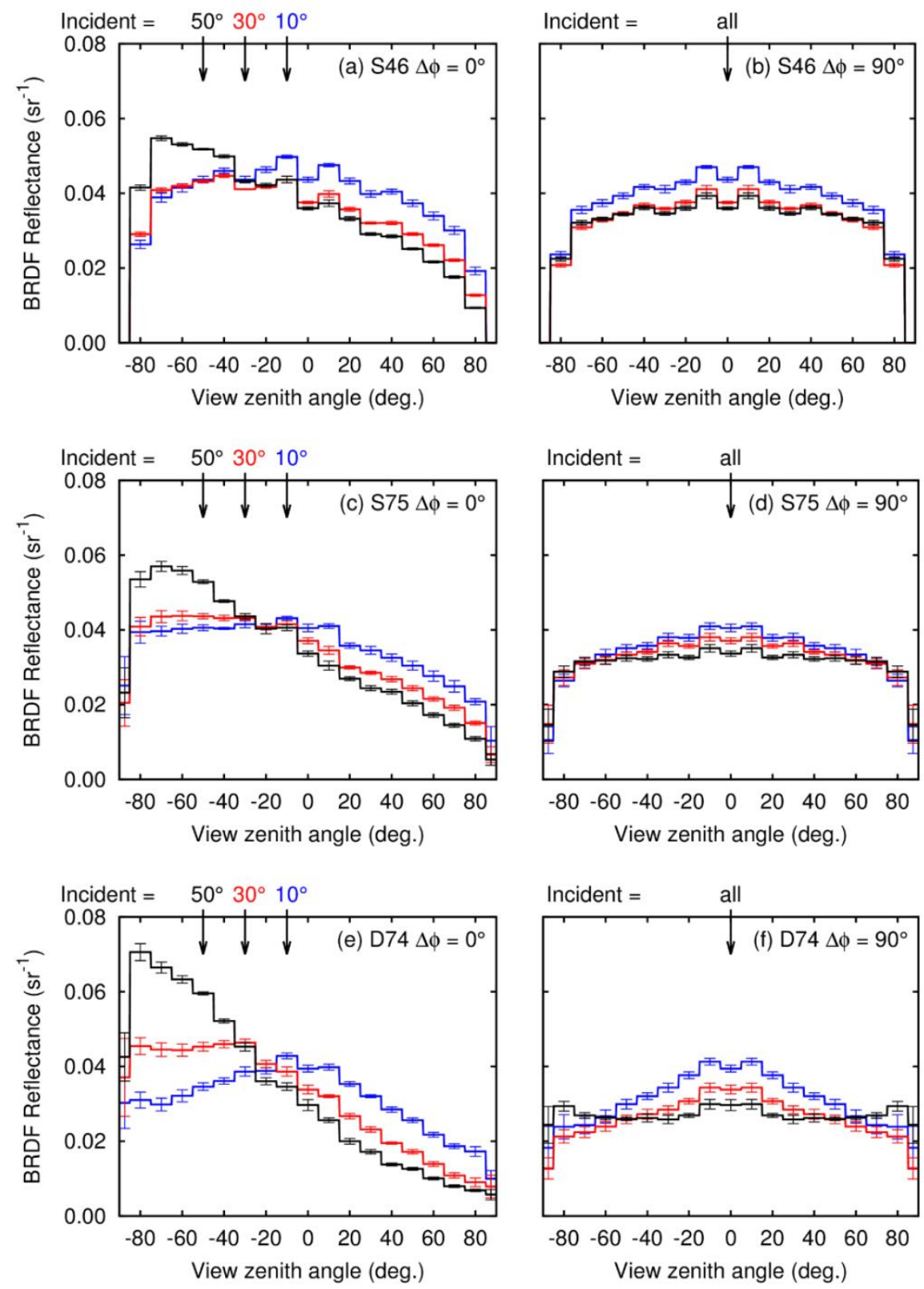

Figure 9. Bidirectional reflectance functions (BRDFs) at $550 \mathrm{~nm}$, of three of the composite coral canopies for shallow (S, 0-10 m) and deep (D, 10-20 m) corals with areal cover: (a,b) 46\%; (c,d) 75\%; and (e,f) 74\%, in the incident plane $\left(\mathrm{a}, \mathrm{c}, \mathrm{e}, \Delta \varphi=0^{\circ}\right)$ and at $90^{\circ}$ to the incident plane $\left(\mathbf{b}, \mathbf{d}, \mathbf{f}, \Delta \varphi=90^{\circ}\right)$. Arrows show direction of incident light, each plot shows $\theta \mathrm{i}$ of $10^{\circ}, 30^{\circ}$ and $50^{\circ}$. Negative view zenith angle for $\Delta \varphi=0^{\circ}$ (a,c,e) means backward reflection (source and view point in the same hemisphere). Error bars are \pm 1 standard error on 12 values from assumed reciprocity, rotational and mirror symmetries.

\subsection{Above-Water BRDF Effects}

Canopy BRDFs contributed to the directional pattern in water leaving radiance under naturalistic sky illumination primarily for dense canopies in shallow, clear water (Figure 10). For the $46 \%$ cover canopy, S46, a slight BRDF effect of increased retro-reflection in the incident plane, leading to effective propagation of the hotspot effect, was evident for depths less than $5 \mathrm{~m}$ with a low sun position, $\theta_{\mathrm{s}}=50^{\circ}$ (Figure 10a). In deeper waters and at $90^{\circ}$ to the incident plane $L_{\mathrm{w}}$, it decreased with increased view angle (Figure 10b,d,f). In deeper waters over sparser canopies, the water column itself becomes a contributor to the above water BRDF, where at $10 \mathrm{~m}$ depth the BRDF response in the solar plane (Figure 10a) resembles the response at $90^{\circ}$ to the solar plane (Figure 10b). 

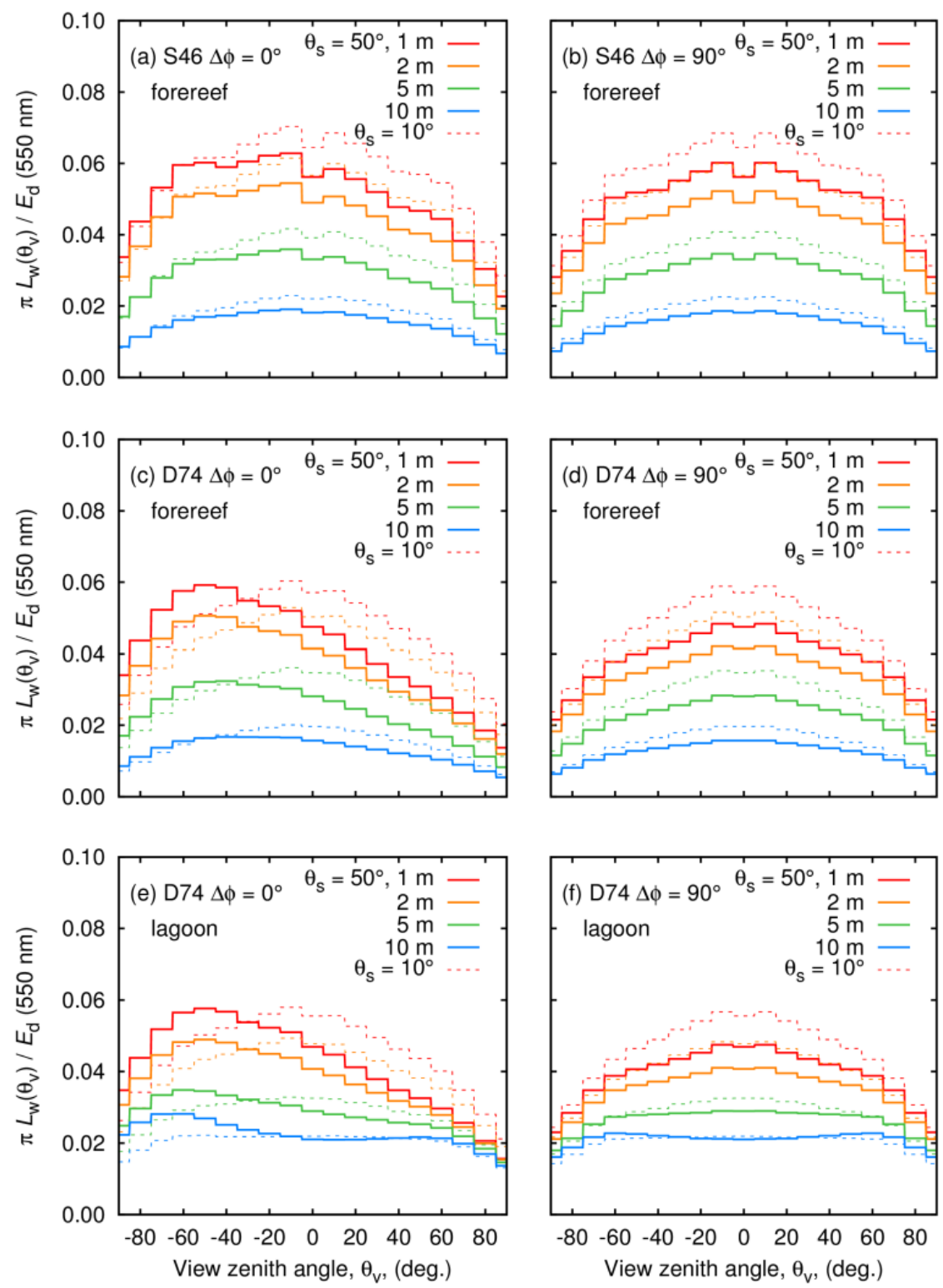

Figure 10. Modelled influence of three-dimensional coral BRDF effects (from Figure 9) on water-leaving reflectance $(\pi \mathrm{Lw} / \mathrm{Ed})$ at $550 \mathrm{~nm}$ for: $(\mathbf{a}, \mathbf{b})$ Composite canopies S46 (46\% shallow coral cover) and; $(\mathbf{c}, \mathbf{d}, \mathbf{e}, \mathbf{f})$ D74 (74\% deep coral cover), in the incident plane $\left(\mathbf{a}, \mathbf{c}, \mathbf{e}, \Delta \varphi=0^{\circ}\right)$ and at $90^{\circ}$ to the incident plane $\left(\mathbf{b}, \mathbf{d}, \mathbf{f}, \Delta \varphi=90^{\circ}\right)$. Each plot shows results of incident solar zenith angles of $10^{\circ}$ (dotted lines) and $50^{\circ}$ (solid lines), and depths $1,2,5$, and $10 \mathrm{~m}$. Negative view zenith angle for $\Delta \varphi=0^{\circ}(\mathbf{a}, \mathbf{c}, \mathbf{e})$ means backward reflection (source and view point in the same hemisphere).

Regarding the dense 74\% coral cover canopy D74, water-leaving BRDF effects in the incident plane were quite prominent for both the forereef IOP treatment and the higher scattering lagoon waters (Figure 10c,e). For example, when the water depth was $1 \mathrm{~m}$, the difference in $L_{\mathrm{w}}(550)$ between a view zenith angle of $50^{\circ}$ toward and away from a sun at $\theta_{\mathrm{S}}=50^{\circ}$ was about a factor of 1.5 ( $\sim 0.06 \mathrm{vs.} \sim 0.04$, Figure 10c,e); whereas this factor was $\sim 1.2$ for view zenith angles at $\pm 20^{\circ}$. At $90^{\circ}$ to the incident plane, even for dense canopies, BRDF effects are less apparent (Figure 10d,f). It is clear that for these modelled canopies, the assumption of a Lambertian bottom is primarily violated close to the retro-reflected (hotspot) direction for large zenith angles $\left(>30^{\circ}\right)$ but could be a more reasonable assumption under other solar-view geometries. The difference in nadir view water-leaving reflectance at $550 \mathrm{~nm}$ for canopy D74 at $1 \mathrm{~m}$, for solar zenith angle of $50^{\circ}$ vs. $10^{\circ}$, was $18 \%$ (Figure $10 \mathrm{c}, \mathrm{d}, \sim 0.047$ vs. $\sim 0.057$ ). This is equivalent to the variation previously shown in reflectance over individual corals under different 
illumination conditions (Figures 4 and 6), which for some corals was as much as $\pm 20 \%$, but here the variation was reduced by the water column, to effectively $\pm 9 \%$. Mobley et al. [31] estimated ignoring non-Lambertian bottom effects would in general, cause errors of less than $10 \%$ in remote sensing reflectance. While not strictly a comparison to a Lambertian bottom assumption, a discrepancy of $18 \%$ implies the potential for larger errors.

To avoid across-swath BRDF effects in airborne imagery, the advice is therefore broadly the same as for avoiding surface glint [32]; thus flying toward or away from the sun will ensure the cross track view is at $90^{\circ}$ to the solar plane, and a solar zenith angle $>30^{\circ}$ both avoids glint and slightly flattens the BRDF response (Figure 10d,f).

\section{Conclusions}

A number of conclusions from this work can be made that relate (1) to using Lambertian bottom boundary conditions and linear mixing models, and (2) to data collection of reflectances and imagery. In summary:

- If the input reflectances for different benthic types can be considered 'pure' surface reflectances, then structural complexity implies the introduction of a shading scale factor or a black shade endmember in mixing models is required. In our data, that shading scale factor could be anywhere from 0.5 to 0.9 , whereas for a genuinely flat substrate it would be 1.0 .

- The magnitude of the shading factor is inversely related to surface rugosity; hence the shade factor value could be set based on the expected bottom types, or if derivable in an image analysis, it would give additional information on benthic type.

- Nadir viewing reflectance over the bottom $\left(L_{\mathrm{u}} / E_{\mathrm{d}}\right)$ for individual corals varies as much as $\sim 20 \%$ (more only in exceptional cases) under the range of light environments found on reefs, under typical remote sensing conditions.

- Regarding view directions beyond a few 10 s of degrees from nadir for dense canopies in shallow water shading, hotspot effects become relevant, leading to potentially a $50 \%$ difference (factor of 1.5) in above water reflectance. At narrower remote sensing geometries (view zenith angles $<20^{\circ}$ ), differences can be $20 \%$ (factor of 1.2 ).

- For all modelled canopy assemblages, there were only small BRDF effects at a relative viewing angle of $90^{\circ}$ to the incident solar plane. The advice for minimizing cross-track BRDF effects in airborne imagery is therefore consistent with that for minimizing surface glint, i.e., fly in a direction close to the solar plane with a solar zenith angle greater than $30^{\circ}$.

- Collection of in-situ spectra of benthic types requires consideration of what level of shading is already included, or whether the data is close to being a surface reflectance measurement. However, including shading in field measurements cannot fully accommodate the influence of canopy interactions, because there are effects at canopy scale involving different benthic types.

- These modelling results provide useful concepts and parameter ranges, which can assist in the interpretation of empirical data and the development of image processing algorithms.

Author Contributions: Conceptualization J.D.H., H.M.D.; Methodology, J.D.H., M.M., A.W., H.M.D.; Writing-Original draft preparation, J.D.H.; Writing-Review \& Editing J.D.H., M.M., A.W., H.M.D.

Funding: This work was funded by award \#NNX15A32G of the NASA Biodiversity and Ecological Forecasting Program.

Acknowledgments: The authors extend thanks to Brandon Russell and Jeff Godfrey for assistance in data acquisition and field work. Part of Brandon Russell's time was funded by the NASA Ocean Biology and Biogeochemistry program and the COral Reef Airborne Laboratory (CORAL) project. Coral collection was conducted under special activity permit (SAP) 2018-02 issued on 2 February 2017, by the State of Hawaii Department of Land and Natural Resources.

Conflicts of Interest: The authors declare no conflict of interest. The funding sponsors had no role in the design of the study; in the collection, analyses, or interpretation of data; in the writing of the manuscript and in the decision to publish the results. 


\section{References}

1. Hedley, J.D.; Roelfsema, C.M.; Chollet-Ordaz, I.; Harborne, A.R.; Heron, S.F.; Weeks, S.; Skirving, W.J.; Strong, A.E.; Eakin, C.M.; Christensen, T.R.L.; et al. Remote sensing of coral reefs for monitoring and management: A review. Remote Sens. 2016, 8, 118. [CrossRef]

2. Mumby, P.J.; Skirving, W.; Strong, A.E.; Hardy, J.T.; LeDrew, E.F.; Hochberg, E.J.; Stumpf, R.P.; David, L.T. Remote sensing of coral reefs and their physical environment. Mar. Pollut. Bull. 2004, 48, 219-228. [CrossRef] [PubMed]

3. Mumby, P.J.; Green, E.P.; Edwards, A.J.; Clark, C.D. Coral reef habitat-mapping: How much detail can remote sensing provide? Mar. Biol. 1997, 130, 193-202. [CrossRef]

4. Hochberg, E.J.; Atkinson, M.J. Capabilities of remote sensors to classify coral, algae, and sand as pure and mixed spectra. Remote Sens. Environ. 2003, 85, 174-189. [CrossRef]

5. Capolsini, P.; Andréfouët, S.; Rion, C.; Payri, C. A comparison of Landsat ETM+, SPOT HRV, Ikonos, ASTER, and airborne MASTER data for coral reef habitat mapping in South Pacific islands. Can. J. Remote Sens. 2007, 23, 87-200. [CrossRef]

6. Lubin, D.; Li, W.; Dustan, P.; Mazel, C.H.; Stamnes, K. Spectral Signatures of coral reefs: Features from space. Remote Sens. Environ. 2001, 75, 127-137. [CrossRef]

7. Hedley, J.D.; Roelfsema, C.; Phinn, S.R.; Mumby, P.J. Environmental and sensor limitations in optical remote sensing of coral reefs: Implications for monitoring and sensor design. Remote Sens. 2012, 4, 271-302. [CrossRef]

8. Hedley, J.D.; Mumby, P.J. Biological and remote sensing perspectives of pigmentation in coral reef organisms. Adv. Mar. Biol. 2002, 43, 277-317. [PubMed]

9. Mumby, P.J.; Hedley, J.D.; Chisholm, J.R.M.; Clark, C.D.; Ripley, H.; Jaubert, J. The cover of living and dead corals from airborne remote sensing. Coral Reefs 2004, 23, 171-183. [CrossRef]

10. Goodman, J.A.; Ustin, S.L. Classification of benthic composition in a coral reef environment using spectral unmixing. J. Appl. Remote Sens. 2007, 1, 011501.

11. Hochberg, E.J.; Atkinson, M.J. Spectral discrimination of coral reef benthic communities. Coral Reefs 2000, 19, 164-171. [CrossRef]

12. Lesser, M.P.; Mobley, C.D. Bathymetry, water optical properties, and benthic classification of coral reefs using hyperspectral remote sensing imagery. Coral Reefs 2007, 26, 819-829. [CrossRef]

13. Leiper, I.A.; Phinn, S.R.; Roelfsema, C.M.; Joyce, K.E.; Dekker, A.G. Mapping Coral Reef Benthos, Substrates, and Bathymetry, Using Compact Airborne Spectrographic Imager (CASI) Data. Remote Sens. 2014, 6, 6423-6445. [CrossRef]

14. Garcia, R.A.; Lee, Z.; Hochberg, E.J. Hyperspectral Shallow-Water Remote Sensing with an Enhanced Benthic Classifier. Remote Sens. 2018, 10, 147. [CrossRef]

15. Joyce, K.E.; Phinn, S.R. Bi-directional reflectance of corals. Int. J. Remote Sens. 2002, 23, 389-394. [CrossRef]

16. Miller, I.; Foster, B.C.; Laffan, S.W.; Brander, R.W. Bidirectional reflectance of coral growth-forms. Int. J. Remote Sens. 2016, 37, 1553-1567. [CrossRef]

17. Hedley, J.D.; Mumby, P.J.; Joyce, K.E.; Phinn, S.R. Spectral unmixing of coral reef benthos under ideal conditions. Coral Reefs 2004, 23, 60-73. [CrossRef]

18. Hedley, J.D. A three-dimensional radiative transfer model for shallow water environments. Optics Express 2008, 16, 21887-21902. [CrossRef] [PubMed]

19. Mobley, C.D.; Sundman, L. Hydrolight 5.2 User's Guide. Sequoia Scientific. Available online: https: / / www.sequoiasci.com/wp-content/uploads/2013/07/HE52UsersGuide.pdf (accessed on 25 July 2018).

20. Young, G.C.; Dey, S.; Rogers, A.D.; Exton, D. Cost and time-effective method for multi-scale measures of rugosity, fractal dimension, and vector dispersion from coral reef 3D models. PLoS ONE 2017, 12, e0175341. [CrossRef] [PubMed]

21. Hedley, J.D.; Enríquez, S. Optical properties of canopies of the tropical seagrass Thalassia testudinum estimated by a three-dimensional radiative transfer model. Limnol. Oceanogr. 2010, 55, 1537-1550. [CrossRef]

22. Hedley, J.D.; McMahon, K.; Fearns, P. Seagrass canopy photosynthetic response is a function of canopy density and light environment: A model for Amphibolis griffithi. PloS ONE 2014, 9, e111454. [CrossRef] [PubMed] 
23. Hedley, J.D.; Russell, B.; Randolph, K.; Dierssen, H. A physics-based method for the remote sensing of seagrasses. Remote Sens. Environ. 2015, 174, 134-147. [CrossRef]

24. Mobley, C.D. Light and Water: Radiative Transfer in Natural Waters; Academic Press: San Diego, CA, USA, 1994; ISBN 0-12-502750-8.

25. Russell, A.B.; Hochberg, E.; Dierssen, H.M. Comparison of water column optical properties across geomorphic zones of Pacific coral reefs. Limnol. Oceanogr. under review.

26. Adams, J.B.; Smith, M.O.; Johnson, P.E. Spectral mixture modelling: A new analysis of rock and soil types at the Viking Lander I site. J. Geophys. Res. 1986, 91, 8098-8112. [CrossRef]

27. Dekker, A.G.; Phinn, S.R.; Anstee, J.; Bissett, P.; Brando, V.E.; Casey, B.; Fearns, P.; Hedley, J.; Klonowski, W.; Lee, Z.P.; et al. Intercomparison of shallow water bathymetry, hydro-optics, and benthos mapping techniques in Australian and Caribbean coastal environments. Limnol. Oceanogr. Methods 2011, 9, 396-425. [CrossRef]

28. Roelfsema, C.M.; Marshall, J.; Phinn, S.R.; Joyce, K. Underwater Spectrometer System 2006 (UWSS04)—Manual; Biophysical Remote Sensing Group, Centre for Spatial Environmental Research, University of Queensland: Queensland, Australia, 2006.

29. Roelfsema, C.M.; Phinn, S.R. Spectral Reflectance Library of Healthy and Bleached Corals in the Keppel Islands, Great Barrier Reef. PANGAEA. Available online: https:/ / doi.org/10.1594/PANGAEA.872507 (accessed on 25 July 2018).

30. Liang, S. Quantitative Remote Sensing of Land Surfaces; Wiley: Hoboken, NJ, USA, 2004; ISBN 978-0471281665.

31. Mobley, C.D.; Zhang, H.; Voss, K.J. Effects of optically shallow bottoms on upwelling radiances: Bidirectional reflectance distribution function effects. Limnol. Oceanogr. 2003, 48, 337-345. [CrossRef]

32. Kay, S.; Hedley, J.D.; Lavender, S. Sun glint correction of high and low spatial resolution images of aquatic scenes: A review of methods for visible and near-infrared wavelengths. Remote Sens. 2009, 1, 697-730. [CrossRef]

(C) 2018 by the authors. Licensee MDPI, Basel, Switzerland. This article is an open access article distributed under the terms and conditions of the Creative Commons Attribution (CC BY) license (http:// creativecommons.org/licenses/by/4.0/). 